\title{
Qualidade de vida no trabalho: um relato sobre manicures
}

Quality of life at work: a report about manicures

Calidad de vida en el trabajo: un relato sobre manicuras

Recebido: $15 / 10 / 2017$

Aprovado: 03/07/2018

Publicado: 27/09/2018
Iranise Moro Pereira Jorge ${ }^{1}$

Kelly Hellmann Dario ${ }^{2}$

Amanda Nascimento Oliveira Belletti ${ }^{3}$

Sendo o trabalho umas das áreas de ocupação, o terapeuta ocupacional contribui para a prevenção e promoção da saúde no contexto laboral. Esta pesquisa tem por objetivo identificar a qualidade de vida de profissionais do serviço de manicure e pedicure. Utilizou-se metodologia com abordagem quantitativa, exploratória, descritiva e de caráter transversal. A coleta de dados aconteceu no segundo semestre de 2012, sendo utilizados uma anamnese e o questionário denominado de WHOQOL-Bref, contando com a participação de 31 pessoas de um salão de beleza em Curitiba/PR. Os resultados apontam baixo escore para o domínio Relações Sociais (Autoestima e Relações Pessoais) e uma pontuação alta para o domínio Físico (Energia e Capacidade de Trabalho). Conclui-se que para uma qualidade de vida satisfatória almeja-se um equilíbrio entre as diversas áreas de ocupação humana, visando saúde e bem-estar.

Descritores: Trabalho; Qualidade de vida; Terapia ocupacional; Centros de embelezamento e estética.

Work is an area of professional performance, and thus, the occupational therapist contributes to the prevention and promotion of health in the context of labor. This research aims to identify the quality of life of professionals in the manicure and pedicure services. A methodology with quantitative, exploratory, descriptive and cross-sectional approach was used. Data collection took place in the second half of 2012, using an anamnesis and questionnaire called WHOQOLBref, with the participation of 31 people from a beauty salon in Curitiba/PR. The results indicated a low score for the Social Relations domain (Self-esteem and Personal Relationships), and a high score for the Physical domain (Energy and Work Capacity). It was concluded that for a satisfactory quality of life, one must seek balance between the different areas of human occupation, aiming at better health and wellbeing.

Descriptors: Work; Quality of life; Occupational therapy; Beauty and aesthetics centers.

Siendo el trabajo una de las áreas de ocupación, el terapeuta ocupacional contribuye a la prevención y promoción de la salud en el contexto laboral. Esta investigación tiene como objetivo identificar la calidad de vida de profesionales del servicio de manicuría y pedicuría. Se utilizó metodología con abordaje cuantitativo, exploratorio, descriptivo y de carácter transversal. La colecta de datos ocurrió en el segundo semestre de 2012, siendo utilizada una anamnesis y un cuestionario denominado WHOQOL-Bref, contando con la participación de 31 personas de un salón de belleza en Curitiba/PR. Los resultados apuntan una baja puntuación para el dominio Relaciones Sociales (Autoestima y Relaciones Personales), y una puntuación alta para el dominio Físico (Energía y Capacidad de Trabajo). Se concluye que, para una calidad de vida satisfactoria, se pretende un equilibrio entre las diversas áreas de ocupación humana, con el fin de conseguir salud y bienestar.

Descriptores: Trabajo; Calidad de vida; Terapia ocupacional; Centros de belleza y estética.

1. Terapeuta ocupacional. Mestre e Doutora em Engenharia de Produção. Docente do Departamento de Terapia Ocupacional Universidade Federal do Paraná (UFPR). Membro do Laboratório de Reabilitação, Acessibilidade e Trabalho, Curitiba, PR, Brasil. ORCID:0000-0001-9014-6801 E-mail: iranise@ufpr.br

2. Terapeuta ocupacional. Curitiba, PR, Brasil. ORCID: 0000-0002-1851-4531 E-mail: kelly_hellmann@hotmail.com

3. Graduanda do Curso de Terapia Ocupacional da UFPR, Curitiba, PR, Brasil. ORCID:0000-0003-4463-7874 E-mail: amandan.oliveira@gmail.com 


\section{INTRODUÇÃO}

$\mathbf{0}$ trabalho vai além do ato de trabalhar ou de vender sua força de trabalho em busca de remuneração. É através do trabalho que ocorre o processo de alteração da natureza e de autotransformação do próprio ser. Logo, o trabalho é entendido como construtor da identidade, pois gera significado para si próprio e para o objeto em si, em um contexto de subjetividade humana ${ }^{1}$.

0 trabalho determina um processo onde permite que o ser humano desenvolva habilidades, bem como exige esforço para que aconteça. Toda a ação realizada está embasada em conhecimento que, ao ser exposto, evidencia os saberes dos indivíduos apreendidos em sua prática, sendo que, independente da tarefa exercida, o trabalho adquire um sentido diferente para cada indivíduo ${ }^{1,2}$.

A indústria da beleza pessoal no Brasil está em franca expansão, tanto na criação de produtos cosméticos, de higiene pessoal, quanto na criação e expansão de serviços ${ }^{3}$. Conforme o Anuário 2012 da Associação Brasileira da Indústria de Higiene Pessoal em Perfumaria e Cosméticos (ABIHPEC), em 2011 o setor cresceu $4,6 \%$, valor superior ao total geral do Produto Interno Bruto (PIB) brasileiro, que foi de $0,1 \%$; um aumento significativo mesmo com a crise internacional e a alta carga tributária no Brasil ${ }^{4}$.

O serviço de manicure é um dos mais procurados em um salão de beleza, e consiste em cuidar e/ou fazer as unhas 3,5 . Segundo o Serviço Nacional de Aprendizagem Comercial (SENAC), o profissional atuante na área de beleza capacitado para o exercício da profissão de manicure e pedicure é aquele que através das técnicas de manicuro e pedicuro utiliza materiais e equipamentos adequados para realizar o serviço de mãos e pés, de acordo com a necessidade do cliente 6 .

A profissão de manicure, em sua maioria, é exercida por mulheres. Frequentemente manicures atuam em salões de beleza em conjunto com cabeleireiros, maquiadores e outros profissionais ligados à área da beleza. Porém, elas podem trabalhar em suas próprias casas ou no domicílio do cliente. Independentemente de onde é realizada essa atividade, nota-se que essa profissão se caracteriza por profissionais autônomos, com longas jornadas e poucas pausas.

Não por acaso, é também um setor de condições de emprego socialmente inseguras. Enquanto a massa total de trabalhadores brasileiros com registro em carteira foi $67 \%$ em 2014, os ocupados do setor com registro em carteira foram apenas $27 \%$, e apenas $23 \%$ declarou pagar a Previdência Social ${ }^{3}$.

A Lei no 13.352, de 27 de outubro de $2016^{7}$ regulamenta a profissão de manicures e outros profissionais de beleza. Mesmo com a regulamentação da profissão por esta Lei, verifica-se que não é requerida uma formação específica para atuar como manicure. Os profissionais se formam pelo exercício e pela prática, outrossim, existe uma diversidade de cursos e de treinamentos com o objetivo de promover uma base do conhecimento técnico e comportamental, capacitando-os de acordo com as exigências do mercado ${ }^{3}$.

Diversos critérios de higiene e estética são requeridos na profissão de manicure. 0 Artigo $4^{\circ}$ da Lei $^{7}$ que regulamenta a profissão de manicure determina especificamente a esterilização dos instrumentos, tamanha sua importância e especificidade na atuação das manicures ${ }^{7}$.

Relata-se, enquanto procedimentos necessários à profissão, a esterilização do material utilizado para evitar a transmissão de doenças, habilidade para manejar objetos pequenos e/ou perfuro cortantes, senso de estética aprimorado, acuidade visual em condições favoráveis, habilidade na comunicação e bom entendimento dos pedidos vindos de clientes, assim como capacidade de concentração e constante aprimoramento na área ${ }^{8}$.

0 trabalho em salões de beleza é uma atividade desgastante, pois envolve contato e atendimento ao público, e a manipulação de produtos químicos, que podem causar problemas à saúde; além disto, manicures passam boa parte do expediente de seu trabalho em pé ou curvados sobre o cliente, causando mal-estar ou lesões por esforço repetitivo ${ }^{9}$. Estudo aponta que as principais queixas dessa categoria são: dores lombares 
decorrentes de má postura; ritmo acelerado de trabalho; atividade exercida sem pausas, bem como sobrecarga física e mental no cotidiano laboral ${ }^{10}$.

Nesse sentido, estudar a qualidade de vida no trabalho (QVT) é relevante para profissionais envolvidos no mundo da gestão e da saúde, pois a boa qualidade das condições ambientais e organizacionais impacta positivamente, proporcionando satisfação. Por sua vez, condições ruins de trabalho impactam negativamente através do sofrimento pelo trabalho exercido e afetam diretamente a própria organização pelo adoecimento e afastamento do trabalhador.

$\mathrm{O}$ termo qualidade de vida (QV), segundo a Organização Mundial da Saúde (OMS), pode ser definido como: “[...] a percepção do indivíduo de sua posição na vida no contexto da cultura e sistema de valores nos quais ele vive e em relação aos seus objetivos, expectativas, padrões e preocupações ${ }^{11}$ ". No que se refere à QVT, a mesma envolve aspectos físicos, ambientais e psicológicos do ambiente laboral. A QVT pode ser entendida como um conjunto de ações de uma empresa ou organização a fim de promover e implementar melhorias, inovações tecnológicas, gerenciais e estruturais ${ }^{12,13}$.

A QVT é observada através dos seguintes enfoques: grau de satisfação da pessoa com a empresa; condições ambientais gerais; e promoção da saúde ${ }^{14}$. Estudos ergonômicos ${ }^{15}$ apontam que os movimentos repetitivos, o emprego de força e posturas incorretas adotadas durante o trabalho, aliados a fatores ligados à organização da atividade e ao ambiente, ocorrem frequentemente, e podem acarretar problemas de saúde, aumentando o absenteísmo e afetando as demais esferas da atividade humana.

A Terapia ocupacional, com seus conceitos e bases teóricas, como forte aliada do entendimento da organização do trabalho e dos aspectos subjetivos da atividade laboral, pode minimizar, em sua prática, os efeitos de um ambiente físico e organizacional de trabalho inadequado.

0 terapeuta ocupacional pode agir junto à organização, aos trabalhadores ou no ambiente de trabalho, proporcionando uma modificação no ambiente, nas tarefas executadas, garantindo uma mudança positiva nesta área de ocupação humana. Este profissional é capaz de intervir na relação do trabalhador com seu trabalho, levando prioritariamente em consideração o ambiente de trabalho, os aspectos filosóficos e organizacionais da organização ${ }^{16}$.

De forma ampliada, a intervenção terapêutica ocupacional envolve ações educativas, preventivas, de promoção e de reabilitação. Estas práticas podem ser possíveis com os indivíduos que apresentam déficits na sua atividade ou um desempenho não competente no ambiente, fornecendo desta forma suporte para um equilibrio interno do trabalhador ${ }^{17,18}$. Assim, esta pesquisa tem por objetivo identificar a qualidade de vida de profissionais do serviço de manicure e pedicure.

\section{MÉTODO}

Esta pesquisa apresenta uma abordagem de natureza quantitativa, exploratória descritiva e de caráter transversal, desenvolvida por uma ação do Laboratório de Reabilitação Acessibilidade e Trabalho (LABRAT) do Departamento de Terapia Ocupacional, realizada com indivíduos inseridos em um contexto de vida real sob influência de questões contemporâneas ${ }^{19}$.

0 contexto de estudo ocorreu no período de julho a novembro de 2012, na unidade principal de uma rede de salões de beleza, localizada na cidade de Curitiba/PR, existente desde o ano de 1971, que atualmente possui 34 unidades no município e região metropolitana.

Como critério de inclusão para a participação na pesquisa escolheu-se a Unidade Central da rede de salões de beleza. A amostra da pesquisa foi constituída somente com manicures que se interessaram voluntariamente em participar do estudo. Das 60 manicures que atuavam na unidade, 31 participaram da referida pesquisa, dessas, 12 trabalhadoras tiveram dificuldade em compreender as questões propostas no WHOQOL-Bref e solicitaram auxílio para responder. 
Para a coleta de dados utilizou-se uma anamnese e o WHOQOL-Bref. A anamnese teve a finalidade de identificar o perfil da amostra pesquisada, sendo solicitadas informações como: idade, gênero, número de filhos, cargo desempenhado, tempo de serviço na instituição, média de atendimentos diários e informações relacionadas a afastamentos por motivo de doença e sua duração.

0 questionário WHOQOL-Bref, um instrumento validado pela Organização Mundial de Saúde, é composto por 26 questões, sendo duas questões gerais e outras que indicam as 24 facetas as quais compõem 4 domínios, que são: Físico, Psicológico, Relações Sociais e Meio Ambiente ${ }^{11}$. A saber:

1. Domínio Físico: composto por perguntas relacionadas a dor e desconforto; energia e fadiga; sono e repouso; mobilidade; atividades da vida cotidiana; dependência de medicação ou de tratamentos e capacidade de trabalho;

2. Domínio Psicológico: contempla os sentimentos positivos; o pensar, aprender, memória e concentração; auto-estima; imagem corporal e aparência; sentimentos negativos e a espiritualidade/religião/crenças pessoais;

3. Domínio Relações Sociais: composto por relações pessoais; suporte (apoio) social e atividade sexual;
4. Domínio Meio Ambiente: contempla a segurança física e proteção; ambiente no lar; recursos financeiros; cuidados de saúde e sociais; disponibilidade e qualidade; oportunidades de adquirir novas informações e habilidades; participação em oportunidades de recreação/lazer e o ambiente físico (poluição/ruído/trânsito/clima).

As respostas ao WHOQOL-Bref seguem uma escala de 1 a 5 , na qual quanto maior a pontuação, melhor a qualidade de vida.

Para análise dos dados, utilizou-se uma planilha, desenvolvida no sistema Microsoft Excel, na qual foram realizados os cálculos de escores e estatística descritiva, além da conversão das facetas invertidas para a escala normal, tornando-as passíveis de comparações com as demais facetas ${ }^{20}$.

Este estudo obteve aprovação pelo Comitê de Ética e Pesquisa do Setor de Ciências da Saúde da UFPR, sob CAAE: 0486.0.000.091-1.

\section{RESULTADOS}

A anamnese inicial (Tabela 1) mostra que em relação à idade houve predominância da faixa etária de 31 a 40 anos (35\%), seguida da faixa etária de até 20 anos (13\%). A maior parte das trabalhadoras são casadas (52\%) e possui de 0 à 1 filho (52\%). 
Tabela 1. Perfil das manicures entrevistadas, Curitiba, 2012.

\begin{tabular}{|c|c|}
\hline Faixa etária (em anos) & $\%$ \\
\hline 18 a 20 & 13 \\
\hline 21 a 30 & 29 \\
\hline 31 a 40 & 35 \\
\hline$>41$ & 23 \\
\hline \multicolumn{2}{|l|}{ Estado Civil } \\
\hline Casada & 52 \\
\hline Divorciada & 6 \\
\hline Solteira & 42 \\
\hline
\end{tabular}

Filhos

\begin{tabular}{cc}
0 & 32 \\
1 & 20 \\
2 & 32 \\
3 ou mais & 16 \\
Tempo de trabalho na instituição & \\
$>1$ ano & 13 \\
1 a 5 anos & 45 \\
$>5$ a 10 anos & 32 \\
$>10$ anos & 10 \\
Atendimento diário & 42 \\
Até 10 & 55 \\
11 a 20 & 3 \\
$>20$ & \\
Afastamento & Sim \\
Não & 90 \\
\hline
\end{tabular}

No que diz respeito ao tempo de serviço prestado no salão, a grande maioria, $45 \%$, possui de um a cinco 5 anos de trabalho e apenas $10 \%$ trabalham no salão há mais de 10 anos (21\%).

Quanto ao número de atendimentos prestados por dia, a maior parte (55\%) atende de 11 a 20 clientes. Considerando que cada atendimento tem duração de 30 minutos, as manicures trabalham de 6 à $10 \mathrm{~h}$ por dia. Nas sextas feiras e sábados, a demanda é aumentada, e a jornada de trabalho é próxima de $10 \mathrm{~h}$.
Em relação ao número de afastamentos por motivos de saúde nota-se que apenas $10 \%$ das entrevistadas tiveram a necessidade de afastamento, tendo como principais motivos: tendinite, fortes dores no corpo e depressão.

Inicialmente foram analisados os resultados obtidos relacionados aos Domínios (Físico, Psicológico, Relações Sociais e Meio Ambiente), possibilitando identificação das médias, desvio padrão e coeficiente de variação geral e por Domínio, como apresentado na Tabela 2.

Tabela 2. Média, Desvio Padrão e Variância dos Domínios do WHOQOL-Bref, Curitiba, 2012.

\begin{tabular}{lccc}
\hline Domínio & Média & Desvio Padrão & Coeficiente de Variação \\
\hline Físico & 12,90 & 2,21 & 17,14 \\
Psicológico & 11,55 & 2,95 & 23,53 \\
Relações Sociais & 11,40 & 5,00 & 43,86 \\
Meio Ambiente & 12,73 & 4,07 & 31,97 \\
Autoavaliação da QV & 10,45 & 4,37 & 41,84 \\
Total & $\mathbf{1 2 , 1 7}$ & $\mathbf{3 , 3 7}$ & $\mathbf{2 7 , 7 2}$ \\
\hline
\end{tabular}


Comparando os resultados obtidos por cada domínio, a menor média, com 10,45 $(\mathrm{DP}=4,37)$ consta na Autoavaliação da QV, e como maior média está o Domínio Físico, com 12,90 de média $(\mathrm{DP}=2,21)$. 0 resultado da média total foi de 12,17 com desvio-padrão igual a 3,37 e variância de 27,72, considerando a amostra.

Com relação a todos os Domínios, o escore total da QV da amostra tem como resultado 42,66, conforme apresentado no gráfico 1. Este valor está abaixo da média considerada um escore de qualidade de vida adequado. Sendo que quanto mais perto de 100, melhor é a QV.

Este escore foi calculado com base na média aritmética simples entre os escores das facetas do instrumento. Tal escore não está presente na sintaxe original do WHOQOL-100. Observa-se que o menor escore $(33,68)$ refere-se às Relações Sociais que abrange relações pessoais, suporte (apoio) social e atividade sexual. 0 maior escore identificado foi no domínio Físico $(51,33)$.

Gráfico 1. Escore de QV por Domínio e Total, Curitiba, 2012.

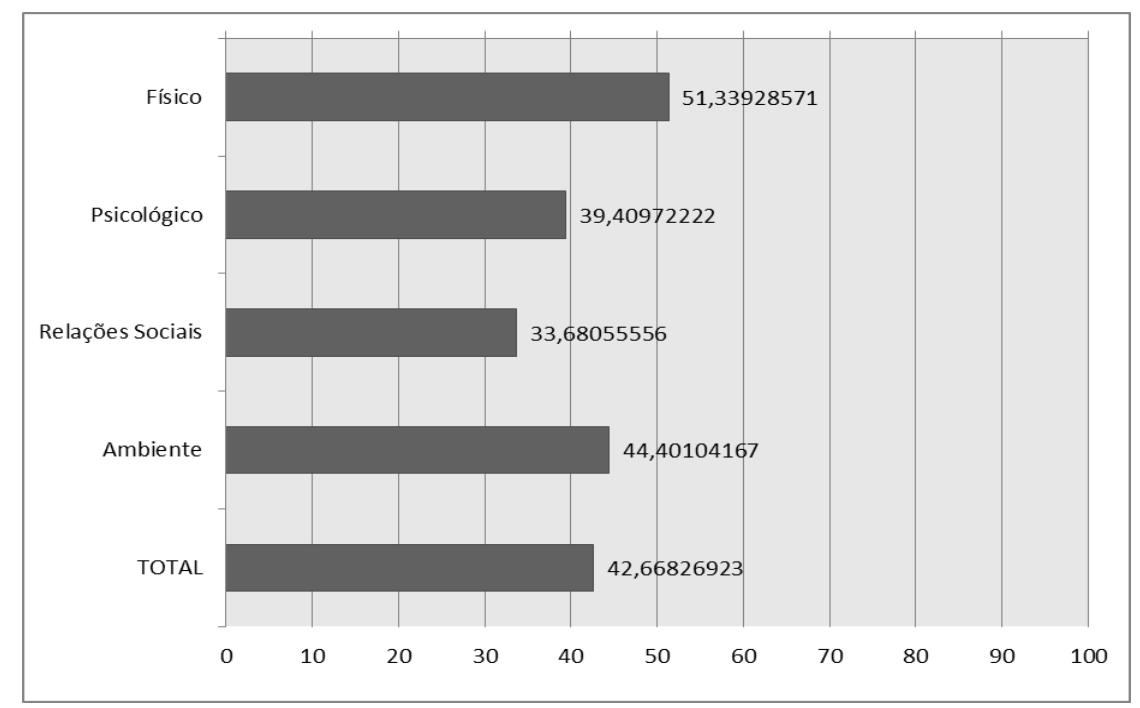

No Gráfico 2 são descritas as facetas e seus respectivos escores. Dentre as 25 facetas, destacam-se com escore mais elevado Energia e Fadiga $(67,70)$ e Capacidade de Trabalho $(61,45)$, o que confirma um percentual elevado no domínio Físico. No entanto, destacam-se de forma estatisticamente significativa com menor escore as facetas de Autoestima $(12,5)$ e Suporte e Apoio Pessoal $(19,79)$, o que confirma o apresentado no resultado obtido no domínio referente às Relações Sociais.

As facetas de Segurança Física e Proteção (25), Ambiente do $\operatorname{Lar}(30,20)$ e Recursos Financeiros $(29,16)$ apresentam a percepção das trabalhadoras com relação à satisfação quanto às condições de moradia, remuneração e segurança, apresentando um resultado de pouca satisfação com esses quesitos. 
Gráfico 2. Escore das Facetas de cada Domínio do WHOQOL-Bref, Curitiba, 2012.

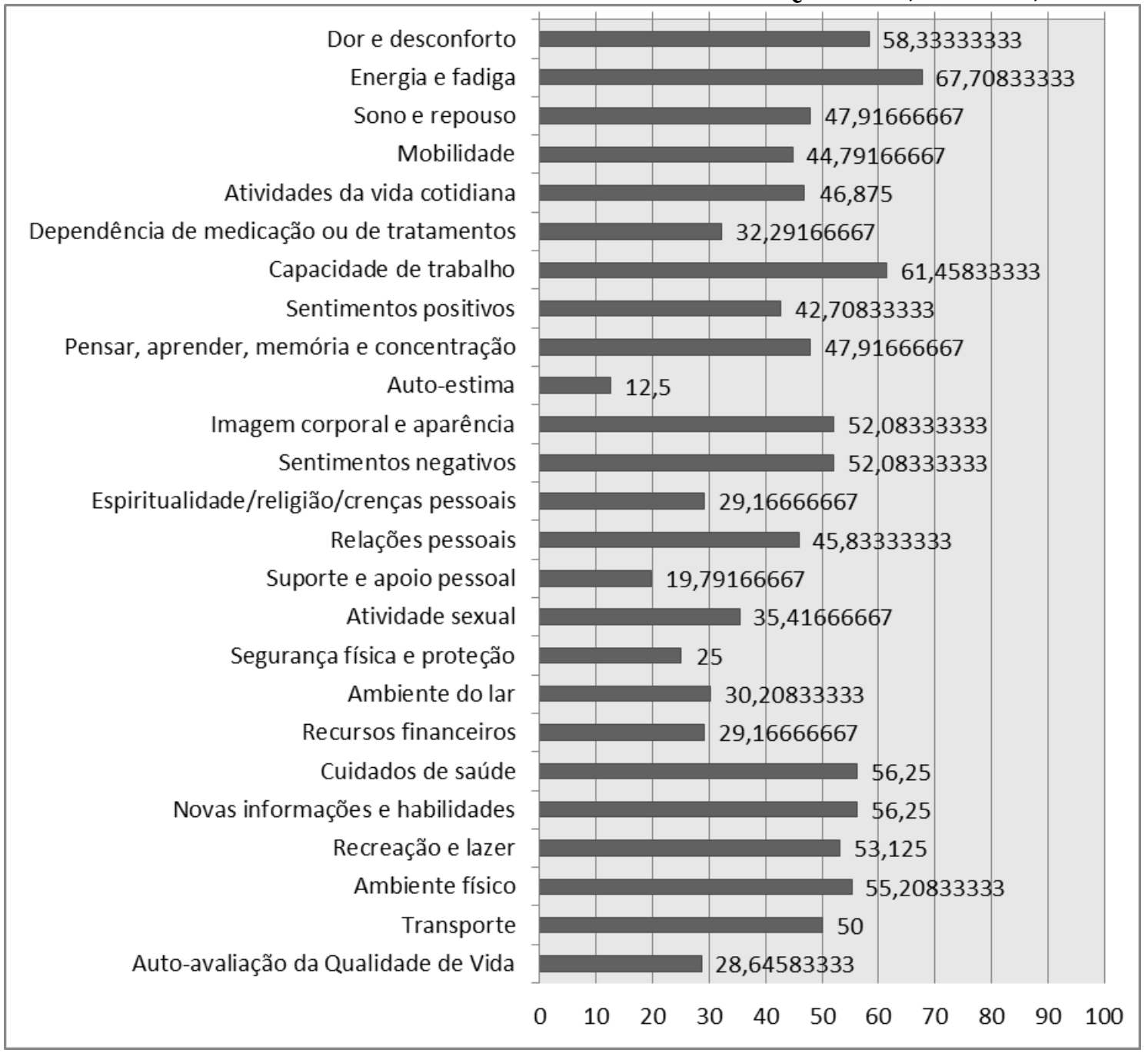

\section{DISCUSSÃO}

Das 34 unidades pertencentes à rede de salões de beleza, a escolhida foi a denominada "Sede Central". Esta foi inaugurada no ano de $2001 \mathrm{e}$ conta com um local onde estão disponíveis aos clientes o espaço de $6.800 \mathrm{~m}^{2}$, espalhados em um prédio de 4 andares, sendo uma garagem e três de serviços.

No primeiro andar localizam-se a lanchonete, banca, algumas lojas de produtos de beleza e acessórios para as clientes, dois banheiros (um feminino e um masculino), 12 lavatórios de cabelos e 20 bancadas de cabelereiros. No segundo andar existe o serviço de maquiagem, onde podem ser observados o trabalho de 10 maquiadoras, dois banheiros (um feminino e um masculino) mais 6 lavatórios de cabelos e mais 8 bancadas de cabelereiros.

No terceiro andar existe o espaço para depilação com 18 cabines e o espaço masculino com 5 bancadas de cabelereiros e barbeiros. Neste andar existe também um mini playground para as crianças brincarem e um espaço especializado para cortes de crianças. As 60 manicures ficam espalhadas pelos três andares realizando suas atividades conforme a solicitação do cliente.

As profissionais manicures, que são o objeto deste estudo, são contratadas após seleção com a proprietária do salão, que faz questão de verificar o trabalho realizado para garantir a qualidade do serviço. 0 salão possui apenas 12 manicures registradas, todas as outras são contratadas como autônomas e recebem por produtividade.

Todas as 60 manicures repassam para o salão $40 \%$ do valor do serviço prestado, para os custos de água, luz, material esterilizado (alicate), outros materiais como: lixa, palitos e toalhas, e pelo próprio espaço físico. Os 
esmaltes e o carrinho onde fazem as unhas devem ser da própria manicure.

A jornada de trabalho das manicures autônomas é determinada pela própria trabalhadora. Têm-se ainda consciência através da jornada de trabalho adotada, a dinâmica de trabalho do salão, referente a dias de folga e dias trabalhados. Trata-se de um modelo de funcionamento no qual se trabalha seis dias por semana, ou até mesmo sete, folgado apenas na segunda-feira pela manhã, quando o salão se encontra fechado.

Não há obrigatoriedade em ir trabalhar aos finais de semana, tampouco de folgar pelo menos um dia durante a semana. Todavia como a remuneração acontece por produtividade, quando não se trabalha não se ganha, fazendo com que as manicures estejam sempre disponíveis ao trabalho. Neste contexto, o terapeuta ocupacional pode atuar como interlocutor entre trabalhadores e organização afim de estabelecer um acordo e/ou normas para o ambiente laboral.

0 número de afastamentos por motivos de saúde não foi representativo. 0 afastamento ocorre apenas quando a dor está insuportável, impedindo a execução do trabalho ou em momentos de crise aguda. Notou-se que as manicures se queixam de dores, porém continuam trabalhando por questões financeiras, uma vez que o salário está relacionado à produção. Há um peso das relações de emprego como fator que influencia o trabalho emocional pela luta da fidelidade das clientes, uma vez que a remuneração ocorre diretamente pela demanda do mercado ${ }^{21}$. Dito de outra forma, para as manicures, quando não há clientes, não há ganho.

Considerando a postura adotada para a execução do trabalho, em que as manicures permanecem grande parte do tempo sentadas com o pescoço flexionado em trabalhos realizados em posição sentada, a maior parte dos músculos abdominais estão relaxados, com um trabalho estático apenas para a estabilização da cintura escapular. Levando em consideração o ponto de vista da atividade muscular, pode-se indicar a posição sentada como de baixo risco para dores na coluna, no entanto, suas estruturas articulares ficam expostas a maiores riscos de lesão ${ }^{22}$.

Nesse contexto, o terapeuta ocupacional pode propor pausas para a realização de alongamento e relaxamento, ao longo do dia, em períodos cuja demanda seja pouca ou até mesmo inexistente.

Em relação aos domínios, o que mais se destaca, apresentando maior índice, foi o Domínio Físico, confirmando os resultados obtidos pela anamnese, em relação a algum tipo de queixa e/ou afastamento por motivo de saúde.

Verifica-se também que o item dependência de medicação e tratamentos apresentou pontuação média. Estudo realizado aponta que $32,0 \%$ sentiam dores na coluna e $35,2 \%$ tomavam medicação ${ }^{23}$. Reflete-se o resultado em relação à pontuação sobre dor e desconforto, uma vez que a pergunta questionava "em que medida você acha que sua dor física impede você de fazer o que precisa?".

Como a maioria das manicures trabalha com dor e realiza suas atividades, a pontuação demonstra um escore maior que $50 \%$. Uma pesquisa ${ }^{24}$ relata que $46,7 \%$ das manicures conviviam com dor diária há mais de 6 meses. Com isso, verifica-se uma falha em saber se existe ou não dor e desconforto no cotidiano laboral.

0 menor escore referiu-se às Relações Sociais. 0 baixo índice neste domínio pode estar relacionado à elevada jornada de trabalho somada ao cansaço, o que dificulta o engajamento nas relações pessoais. A falta de percepção de apoio está diretamente relacionada a investimentos que dão suporte a uma organização interna do trabalhador.

Com relação ao suporte social, vinculase à estruturação da organização do trabalho e dos conflitos existentes no ambiente de trabalho com as colegas ${ }^{18}$. Além disso, apresenta o maior escore no Domínio Físico, que mesmo com as queixas já apresentadas em relação a dores, obteve um alto índice, decorrente dos itens de satisfação com sua capacidade, energia para desempenhar as atividades no dia a dia e no trabalho, e capacidade de se locomover. 
Observa-se que a faceta Suporte e Apoio Pessoal é uma das 25 facetas com menor avaliação. Essa situação foi identificada na fala das trabalhadoras, segundo a qual os conflitos no ambiente de trabalho interferem significativamente na satisfação com as relações pessoais, pois a percepção de apoio recebido pelas colegas é mínima.

Com relação às facetas que correspondem a Sentimentos Positivos e Sentimentos Negativos, o trabalho é um mediador central da construção, desenvolvimento e complementação do indivíduo, e essa relação torna-se geradora de adoecimento ou prazer ${ }^{1}$. Dessa forma, ao observar os resultados correspondentes a estas duas facetas, o trabalho pode ter contribuído para um aumento de sentimentos negativos expressado em maior proporção entre as trabalhadoras.

Em alguns períodos do ano a demanda é maior e em outros meses é menor, o que dificulta na organização orçamentária familiar, influenciando nos bens adquiridos para organização do lar, assim como na escolha do local de moradia que impactará em sua segurança. Essas percepções são notadas quando as facetas de Segurança Física e Proteção e Recursos Financeiros apresentam escores baixos referindo a pouca satisfação.

Levando-se em consideração a carga de trabalho elevada das manicures observa-se que o tempo do não trabalho é influenciado de forma que impossibilita a realização de atividades de lazer. Porém, a faceta correspondente a Recreação e Lazer aponta um escore alto, indicando que, mesmo com alta demanda de trabalho, não ocorre nesta amostra uma redução significativa do aproveitamento do tempo fora do trabalho.

A faceta que corresponde à Autoavaliação da QV obteve uma pontuação muito baixa. Este valor indica que as trabalhadoras apresentavam insatisfação com as condições atuais de qualidade de vida e saúde, sendo estas reflexo das práticas cotidianas e da realidade vivida pelas populações ${ }^{18}$.

Com base na análise dos dados e resultados obtidos nesta pesquisa, os terapeutas ocupacionais do estudo elaboraram algumas ações referentes à organização e dinâmica do trabalho, as quais foram apresentadas para trabalhadores e gestores. São elas:

a) estabelecimento de um horário de almoço pré-definido e uma folga semanal/obrigatória através do sistema de rodízio de grupo. Dessa forma, ao retornar ao trabalho, as manicures estariam descansadas e mais dispostas, podendo, inclusive, aumentar a sua produtividade, bem como a qualidade de atendimento e prestação do serviço;

b) proposta e organização de opções de locais adequados de descanso durante o horário de almoço e intervalos, propiciando maior qualidade durante o desenvolvimento das atividades laborais e até mesmo uma maior organização de rotina;

c) desenvolvimento de uma cartilha, como um recurso visual de suporte, contendo os principais alongamentos e facilitando a realização correta dos movimentos;

d) sugestão da organização de uma comissão responsável por levantar as necessidades comuns das trabalhadoras, identificando assim as demandas e interesses, de forma a garantir os serviços e o bem-estar.

\section{CONCLUSÃO}

As manicures apresentaram qualidade de vida deficitária, sendo essa situação verificada a partir dos domínios identificados através da aplicação do WHOQOL-Bref. Também, foi possível verificar a interferência que o trabalho causa nas áreas de ocupação.

Nesse sentido, o terapeuta ocupacional, através de um serviço de consultoria em saúde do trabalhador, está apto a elaborar projetos de ações de prevenção e promoção no ambiente de trabalho, bem como de estabelecer uma ponte entre recursos humanos e trabalhadores, mediando as relações entre as partes com vistas a potencializar o desempenho satisfatório no ambiente dos indivíduos nele inseridos.

O ideal para uma qualidade de vida satisfatória seria um equilíbrio entre as diversas ocupações, proporcionando um ajuste entre suas demandas, em todas as esferas da ocupação humana, visando saúde e 
bem-estar. Para isto é necessário o incentivo ao desenvolvimento de programas com o intuito de proporcionar benefícios tanto para vida profissional como pessoal, tendo em vista uma considerável melhora na motivação, criatividade e produtividade das equipes de trabalho.

Ressalta-se que este estudo é pontual e que não se pode generalizar este resultado para toda a categoria de profissionais manicures. Esta situação torna-se um limitador da pesquisa.

Assim, para uma intervenção coerente, faz-se necessária uma análise das queixas levantadas durante o processo de aplicação de questionários. A partir disso é que se pode entender de forma mais ampla o funcionamento e as dinâmicas de relações já existentes na rede de salões de beleza.

Por fim, sugere-se a continuidade de pesquisas com esta categoria profissional, com enfoques mais específicos para continuidade de sugestões referentes à promoção da qualidade de vida e da saúde destas trabalhadoras.

\section{REFERÊNCIAS}

1. Lancman S. Construção de novas teorias e práticas em terapia ocupacional, saúde e trabalho. In: Lancman S. Saúde, trabalho e terapia ocupacional. São Paulo: Roca; 2004. p. 71-83.

2. Gherardi S. Practice? It's a matter of taste! Manage Learn. 2009; 40(5):535-50.

3. Oliveira JA. Fazendo a vida fazendo unhas: uma análise sociológica do trabalho de manicure. [Tese]. São Paulo:Universidade de São Paulo; 2014. 285p.

4. Associação Brasileira da Indústria de Higiene Pessoal Perfumaria e Cosméticos. Anuário 2012. 3.ed. São Paulo: Public Projetos Editoriais; 2012. 149p.

5. Gallon S, Bitencourt BM, Viana DD, Antonello CS. Formas de aprendizagem e saberes no trabalho de manicures. RPCA. 2016; 10(1):96-112. DOI: http://dx.doi.org/10.12712/rpca.v10i1.655 6. Serviço Nacional de Aprendizagem Comercial. Curso livre de técnicas de manicure e pedicure. São Paulo: SENAC-SP; 2013. 45p.
7. Presidência da República (Brasil). Lei $\mathrm{n}^{0}$ 13.352, de 27 de outubro de 2016. Altera a Lei no 12.592, de 18 de janeiro 2012, para dispor sobre o contrato de parceria entre os profissionais que exercem as atividades de Cabeleireiro, Barbeiro, Esteticista, Manicure, Pedicure, Depilador e Maquiador e pessoas jurídicas registradas como salão de beleza [Internet]. D.O.U., Brasília, DF, 28 dez 2016 [citado em 10 jun 2017]. Disponível em: http://www.planalto.gov.br/ccivil_03/_ato20 15-2018/2016/lei/L13352.htm

8. Castro RX. Manicure e Pedicure. 1o ed. Instituto Federal do Norte de Minas. Montes Claros. 2015. [citado em 10 jun 2016]; 1(1):111. Disponível em: http://ead.ifnmg.edu.br/uploads/documento s/1SYHHIZPWb.pdf

9. Bittencourt JÁ, Campos LCN, Chaves FAV, Paulista JES, Matsumoto AS. Qualidade de vida no trabalho nos salões de beleza da cidade Satélite do Riacho Fundo. In: XI Simpósio de Excelência de Gestão e Tecnologia [Internet]; out 2014 [citado em 10 jun 2016]; Resende, RJ. Resende, RJ: Associação Educacional Dom Bosco; $2014 . \quad$ Disponível em: https://www.aedb.br/seget/arquivos/artigo s14/45420530.pdf

10. Fonseca ES, Freitas NC, Fonseca IAS, Cupertino LL, Silva EP, Mafra SCT, et al. Análise Ergonômica do Trabalho em um salão de beleza no município de Viçosa - MG. In: VI Workshop de Análise Ergonômica do Trabalho; III Encontro Mineiro de Estudos em ergonomia; VIII Simpósio do Programa Tutorial em Economia Doméstica [Internet]; jul-2013; Viçosa, MG. Viçosa, MG: UFV; 2013 [citado em 10 jun 2016]. Disponível em: http://www.ded.ufv.br/workshop/docs/anai s/2013/Estela\%20da\%

20Silva $\% 20$ Fonseca $\% 20 \% 20 \% 20 \% 20 \% 20$ \%20\%20Tem\%C3\%A1tica\%20Ergonomia.p df

11. Fleck MPA, Louzada $S$, Xavier $M$, Chachamovich E, Viera G, Santos L. et al. Aplicação da versão em português do instrumento abreviado de avaliação da qualidade de vida "WHOQOL-Bref". Rev Saúde Pública. 2000; 34(2):178-83.

12. Chiavenato I. Gestão de pessoas: o novo papel dos recursos humanos nas 
organizações. Rio de Janeiro: Elsevier; 2010. 569 p.

13. Limongi-França AC, Arellano EB. As pessoas na organização. São Paulo: Gente; 2002. p. 295-312.

14. Limongi França AC. Indicadores empresariais de qualidade de vida no trabalho: esforço empresarial e satisfação dos empregados no ambiente de manufaturas com certificação ISSO 9000. [Tese]. São Paulo: Universidade de São Paulo; 1996. 352p.

15. Queiroz MFF, Maciel RH. Condições de trabalho e automação: o caso do soprador da indústria vidreira. Rev Saúde Pública [Internet]. 2001 [citado em 10 jun 2016]; 35(1):1-9. Disponível em: http://www.scielo.br/pdf/rsp/v35n1/4129. pdf

16. Watanabe M, Nicolau SMA. Terapia ocupacional na interface da saúde e do trabalho. In: De Carlo MMRP, Bartalotti CC. Terapia ocupacional no Brasil: fundamentos e perspectivas. São Paulo: Plexus; 2001. p.155171.

17. Hagedorn R. Ferramentas para a prática em terapia ocupacional, uma abordagem estruturada aos conhecimentos e processos centrais. São Paulo: Roca; 2007.

18. Emmel MLG, Matsukura TS, Martinez CMS, Castro CB. Qualidade de vida e promoção em saúde junto a trabalhadores: uma proposição de diagnóstico e intervenção em terapia ocupacional. Cad Ter Ocup UFSCar. 2002: 10(1):30-41.

19. Godoy AS, Forte D. Competências adquiridas durante os anos de graduação: um estudo de caso a partir das opiniões de alunos formandos de um curso de administração de empresas. Gestão \& Regionalidade. 2007; 23(68):56-69.
20. Pedroso B, Pilatti L, Reis DR. Cálculo dos escores e estatística descritiva do WHOQOL100 utilizando o Microsoft Excel. Rev Bras Qual Vida. 2009; 1(1):23-32.

21. Cohen RL. When it pays to be friendly: employment relationships and emotional labour in hairstyling. Sociol Rev. 2010; 58(2):197-218.

22. Brito PM, Costa CKL, Medeiros Neto CF, Guedes DT, Másculo FS, Cardia MCG, et al. Análise da relação entre a postura de trabalho e a incidência de dores na coluna vertebral. In: XXIII Encontro Nacional de Engenharia de Produção; 2003; Ouro Preto, Brasil. Rio de Janeiro: ABEPRO; 2003. Disponível em: http://www.abepro.org.br/biblioteca/ENEG EP2003_TR0406_1582.pdf

23. Vieira M, Silveira C. Condições de trabalho e vida de manicures de um município de Minas Gerais, Brasil. Rev Port Saúde Ocup. [Internet]. 2016 [citado em 10 jun 2016]; 1(1):1-11. Disponível em: http://www.rpso.pt/condicoes-de-trabalhoe-vida-de-manicures-de-um-municipio-deminas-gerais-brasil/

24. Kinote APBM, Garcia AEA, Vidal LMD, Melo LTM, Vasconcelos RS, Abdon APV. Ocorrência de dor na coluna vertebral e sua relação com a qualidade de vida de manicures e pedicures. Rev Bras Promoç Saúde. 2013; 26(3):318-24.

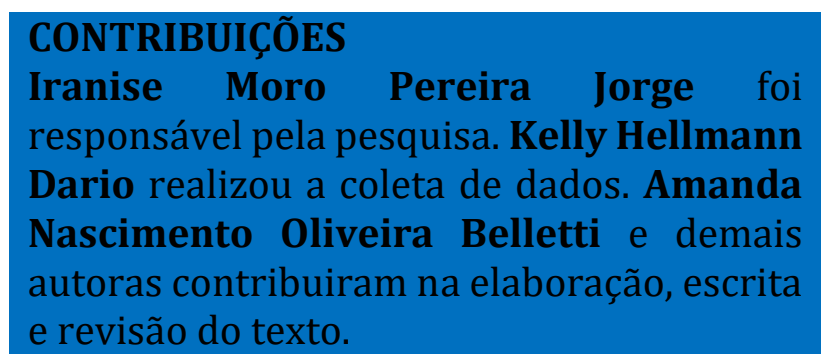

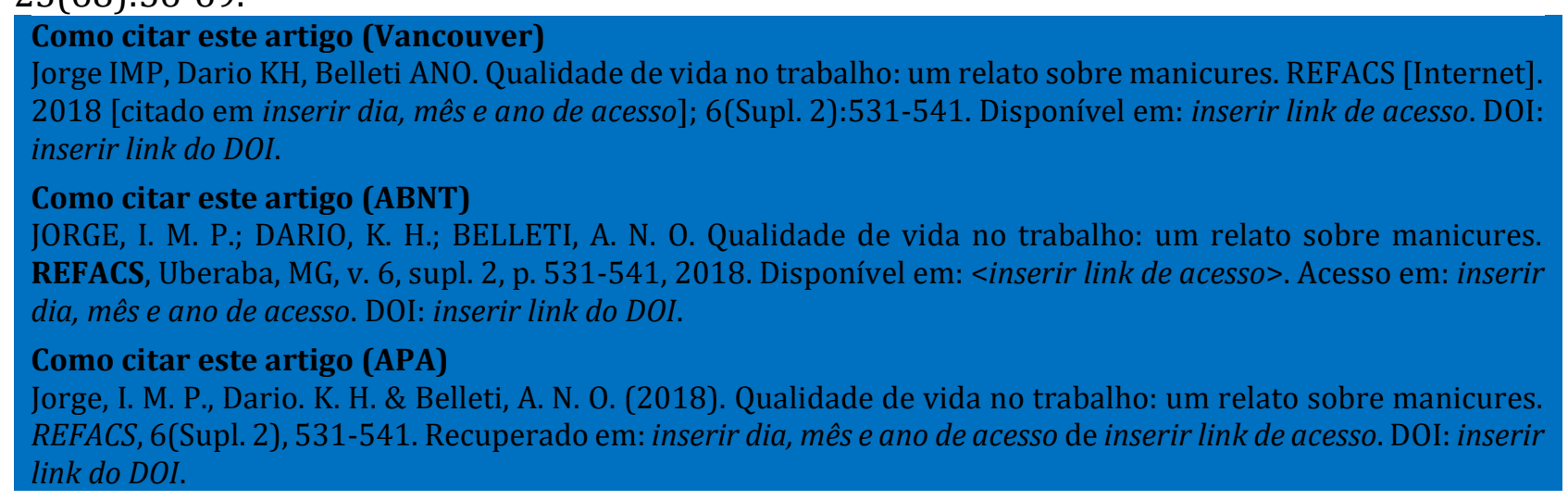

